\title{
Ocular-muscle surgery for filamentary keratitis that developed in double elevator palsy
}

This article was published in the following Dove Press journal: International Medical Case Reports Journal

\section{Osamu Hieda \\ Norihiko Yokoi \\ Chie Sotozono}

Department of Ophthalmology, Kyoto Prefectural University of Medicine, Kyoto, Japan
Correspondence: Osamu Hieda Department of Ophthalmology, Kyoto Prefectural University of Medicine, 465 Kajii-cho, Hirokoji-agaru, Kawaramachidori, Kamigyo-ku, Kyoto 602-084I, Japan Tel +8I 75 25। 5578

Fax +8I $7525 I 5663$

Email ohieda@koto.kpu-m.ac.jp
Purpose: To report a case of filamentary keratitis occurring in the cornea hidden under the eyelids by squint surgery.

Methods: A 69-year-old female patient with a history of amblyopia was referred for intractable filamentary keratitis in the left eye. The strabismus angle was $35 \Delta$ hypertrophic, and ocular motility was within the normal range. Slit-lamp examination of her left eye revealed filamentary keratitis in more than one-third of the upper cornea behind the upper eyelid. Her right eye was diagnosed as supranuclear double elevator palsy. We performed strabismus surgery on her right eye, including inferior rectus muscle recession $(5 \mathrm{~mm})$ in combination with superior rectus muscle resection $(5 \mathrm{~mm})$ under local anesthesia. Following surgery, the left eye squint angle was improved. The filamentary keratitis of the left eye disappeared, and there was no recurrence over the following 5 years.

Conclusion: The squint surgery of paralyzed right eye decreased the strabismus angle, subsequently resulting in the disappearance of the filamentary keratitis in the left eye via the resolution of the relative blepharoptosis. Although the squint operation performed was not for the purpose of improving binocular function, we want to conclude that it can treat the filamentary keratitis behind the eyelid.

Keywords: filamentary keratitis, squint surgery, double elevator palsy, amblyopia

It has been reported that eyelid surgery can effectively treat filamentary keratitis that occurs on the area of the cornea located behind the eyelid. ${ }^{1}$ In general, squint-related surgeries can be used to improve binocular function. However, here we report a case of intractable filamentary keratitis that occurred on the upper cornea at the area behind the upper eyelid, which was successfully treated by a squint operation performed on the contralateral eye.

\section{Case report}

A 69-year-old female patient with a history of amblyopia in her left eye was referred to our department in January 2012 for intractable filamentary keratitis in the left eye. Upon examination, we found that the uncorrected visual acuity in her right eye was 0.6 in decimal and the best-corrected visual acuity was $0.8,-0.5$ diopter (D) for myopia and $-0.5 \mathrm{D}$ for astigmatism with $135^{\circ}$ axis. Both uncorrected and corrected visual acuities in her left eye were 0.08 , which was uncorrectable. In her left eye, the strabismus angle was $35 \Delta$ hypertrophic and ocular motility was within the normal range. Her right eye was the dominant eye, with imperfect upper rotation at 
the inside and outside transposition (Figure 1A) and positive Bell's phenomenon. Hence it was diagnosed as supranuclear double elevator palsy (DEP). Slit-lamp examination of her left eye revealed filamentary keratitis in more than one-third of the upper cornea behind the upper eyelid (Figure 1B-D). An upward restriction of right eye was shown using Hess chart (Figure 1E). The patient explained that she had experienced a long history of severe pain in that eye, and that it had been resistant to a variety of topical treatments. On March 2012, we performed strabismus surgery on her right dominant eye, including inferior rectus muscle recession ( 5 $\mathrm{mm}$ ) in combination with superior rectus muscle resection ( $5 \mathrm{~mm}$ ) under local anesthesia. Following surgery, the left eye squint angle was improved to $5 \Delta$ hypertrophic (Figure 2A). As a combination therapy, a bandage soft contact lens was applied for 2 weeks on her left eye and eye drops containing $0.5 \%$ levofloxacin and $0.1 \%$ fluorometholone were instilled twice daily in that eye for 3 months post operation, and then discontinued. The filamentary keratitis of the left eye disappeared, and there was no recurrence over the following
5 years (Figure 2B, C). After the surgery, uplift limit of right eye was improved (Figure 2D).

Written informed consent was obtained from the patient to publish this case report and the accompanying images.

\section{Discussion}

Filamentary keratitis is a chronic corneal disease characterized by the adherence of filamentous material to the corneal surface. ${ }^{2}$ It has been suggested that the mechanism of this disease is associated with tear abnormalities such as increased mucin in the tear film due to aqueous tear deficiency or facilitated evaporation of tears, or lid abnormalities such as blepharoptosis or sustained eyelid closure. Corneal filaments are reportedly composed of strings of corneal epithelial cells that form the core of the filamentous structure and that are surrounded by mucin, inflammatory cells, and conjunctival epithelial cells $\mathrm{s}^{3}$ that are formed in association with the increased friction between the cornea and eyelid during blinking. ${ }^{4}$ To date, there is no effective treatment for the filament itself. However, it has been reported that eyelid
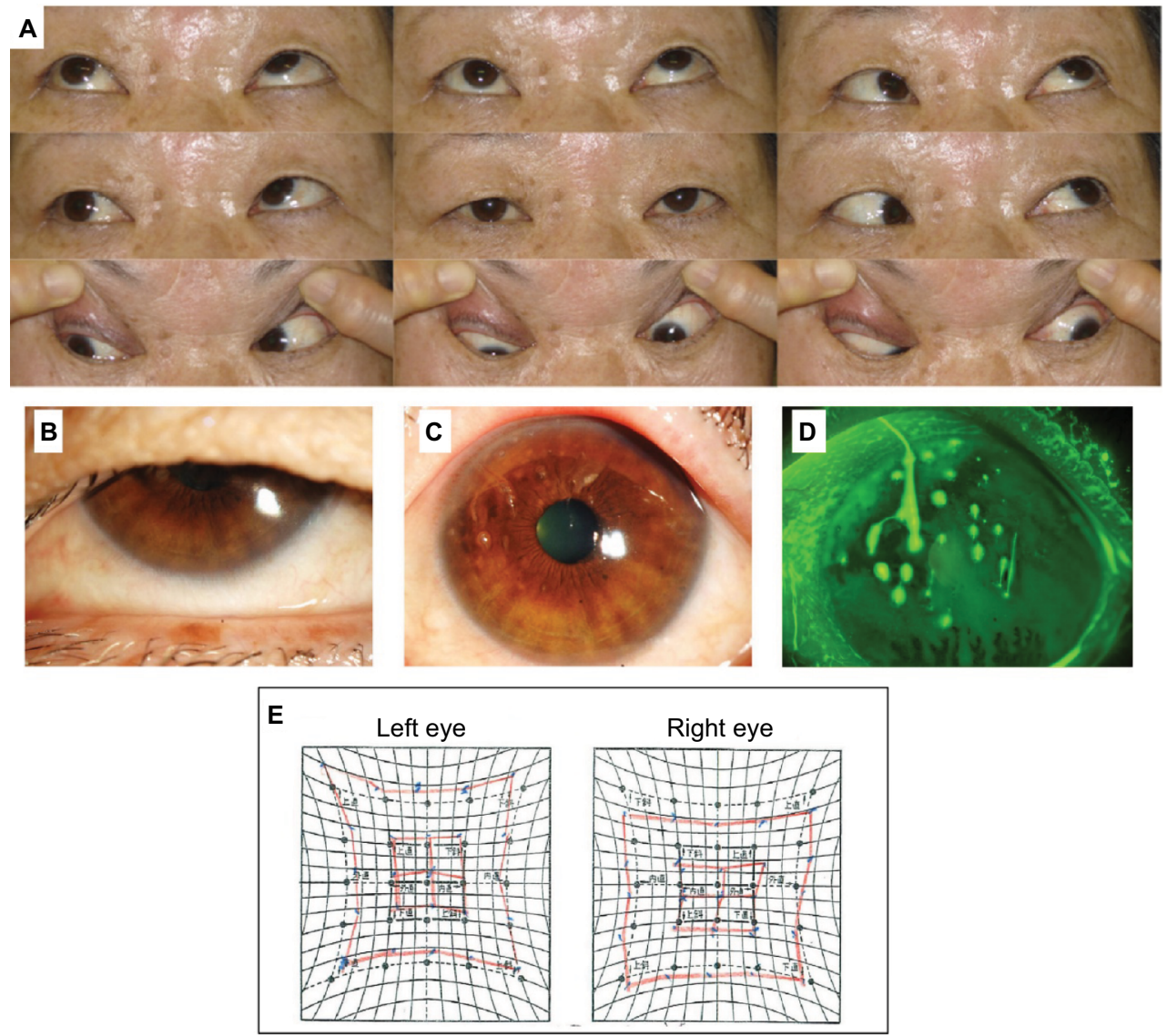

Figure I Preoperative findings.

Notes: (A) Preoperative images of the nine diagnostic gaze positions in a female patient with filamentary keratitis. Prior to surgery, hypertropia was detected in the primary gaze position of her left eye. The patient's right eye was found to have upper rotation imperfection at the inside and outside transposition. (B) Preoperative slitlamp examination image of the patient's left eye. The upper-third or more area of the cornea was covered to the upper eyelid due to an upper squint. (C) A thread-like inflammation of the cornea in the upper-third area of the patient's left eye. (D) Fluorescein staining of the left eye cornea. (E) Hess chart shows an upward restriction on the right eye. 

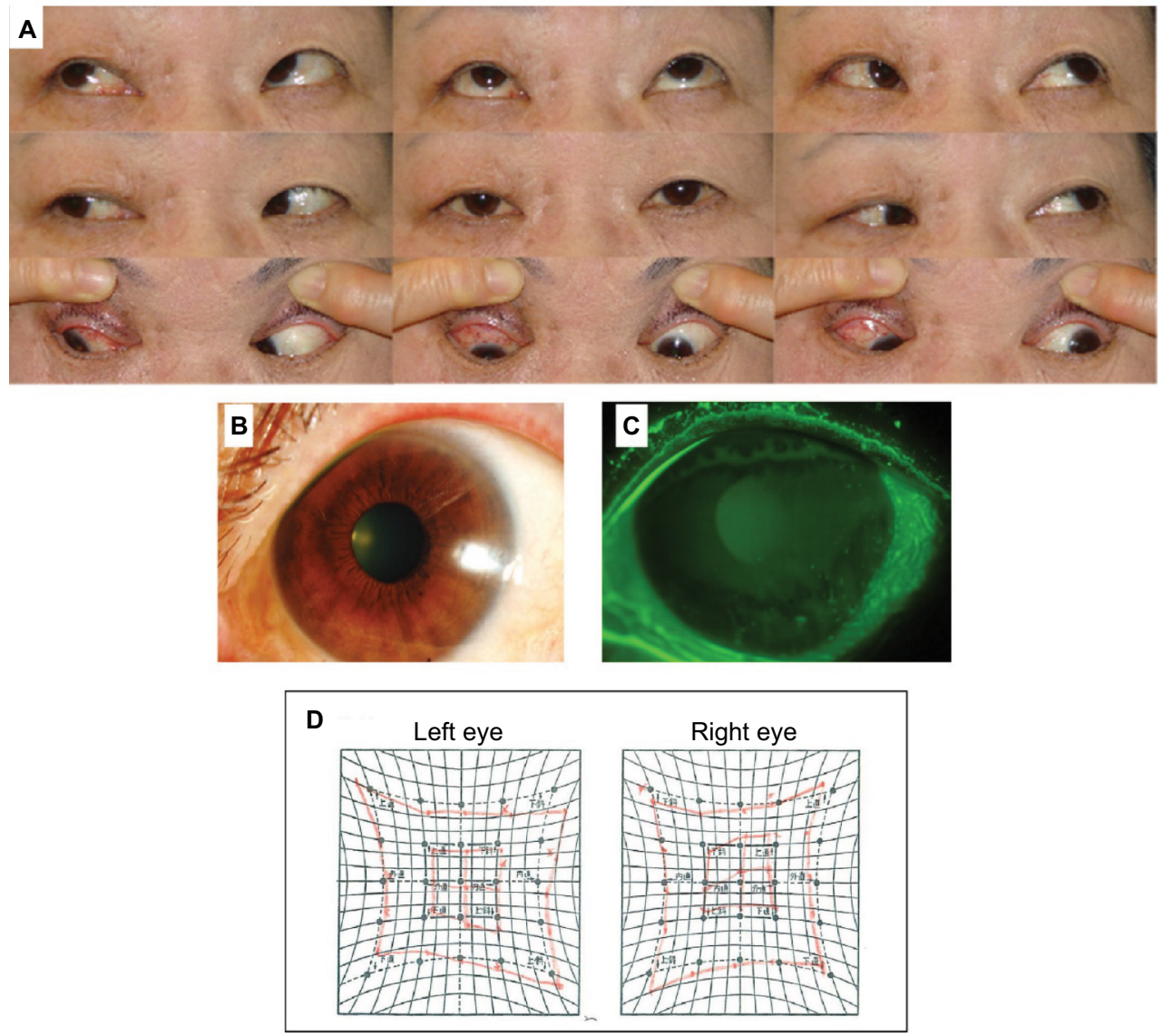

Figure 2 Postoperative findings.

Notes: (A) Images of the patient's nine diagnostic gaze positions at 3 weeks post operation. Her ocular muscles became orthophoria in the primary gaze position, and strabismus significantly decreased in all gaze directions. Her right eye performed upper rotation improved at the inside transposition. (B) Anterior ocular segment findings in the patient's left eye at 3 weeks post operation revealed no filamentary keratitis. (C) Fluorescein staining of the left eye cornea. (D) Hess chart shows improvement of uplift limit of right eye.

surgery is effective for treating cases of filamentary keratitis associated with blepharoptosis. ${ }^{1}$ It has been reported that filamentary keratitis can occur at the area of the cornea hidden behind the eyelids due to strabismus, ${ }^{5}$ yet there are no reports of filamentary keratitis associated with strabismus being successfully treated by strabismus surgery alone. DEP is hypotropia with imperfect upper rotation at the inside and outside transposition. In cases of paralysis eye fixation, the strabismus angle is known to generally become more severe by the Hering's law of equal innervation. ${ }^{6}$ By paralyzed eye surgery, it was expected that the effect will be stronger. Thus, we presumed that the larger angle hyperopia in our patient's left eye resulted in the relative blepharoptosis which led to the filamentary keratitis via increased friction. We carried out a paralytic right eye surgery on the supra-nuclear ophthalmoplegic eye, with the intention of reducing the strabismus angle. If the operation of non-paralyzed left eye was carried out, the effect could be insufficient. The squint surgery of paralyzed right eye decreased the strabismus angle, subsequently resulting in the disappearance of the left eye filamentary keratitis via the resolution of the relative blepharoptosis.

\section{Acknowledgment}

The authors wish to thank John Bush for reviewing the case report.

\section{Disclosure}

The authors report no conflicts of interest in this work.

\section{References}

1. Kitazawa K, Yokoi N, Watanabe A, et al. [Eyelid surgery for refractory filamentary keratitis]. Nihon Ganka Gakkai Zasshi. 2011;115(8): 693-698. Japanese.

2. Hamilton W, Wood TO. Filamentary keratitis. Am J Ophthalmol. 1982;93(4):466-469.

3. Zaidman GW, Geeraets R, Paylor RR, Ferry AP. The histopathology of filamentary keratitis. Arch Ophthalmol. 1985;103(8):1178-1181.

4. Tanioka H, Yokoi N, Komuro A, et al. Investigation of the corneal filament in filamentary keratitis. Invest Ophthalmol Vis Sci. 2009;50(8):3696-3702.

5. Good WV, Whitcher JP. Filamentary keratitis caused by corneal occlusion in large-angle strabismus. Ophthalmic Surg. 1992;23(1):66.

6. ZIFFER A. Monocular elevation deficiency (Double elevator palsy) and Monocular depressor deficiency (Double depressor palsy). In: Rosenbaum AL, Santiago AP, eds. Clinical Strabismus Management, Principle and Surgical Technique. Philadelphia: W.B. Saunders Company, 1999. 
International Medical Case Reports Journal

Dovepress

Publish your work in this journal

The International Medical Case Reports Journal is an international, peer-reviewed open-access journal publishing original case reports from all medical specialties. Previously unpublished medical posters are also accepted relating to any area of clinical or preclinical science. Submissions should not normally exceed 2,000 words or

4 published pages including figures, diagrams and references. The manuscript management system is completely online and includes a very quick and fair peer-review system, which is all easy to use. Visit http://www.dovepress.com/testimonials.php to read real quotes from published authors.

Submit your manuscript here: https://www.dovepress.com/international-medical-case-reports-journal-journal 